\title{
AISLAMIENTO DE BACTERIAS RESISTENTES A ARSENICO DESDE MUESTRAS DE ROCAS VOLCANICAS DE LA QUEBRADA CAMARONES, REGION PARINACOTA. CHILE
}

\author{
ISOLATION OF ARSENIC RESISTANCE BACTERIA FROM VOLCANIC \\ ROCKS OF QUEBRADA CAMARONES, PARINACOTA REGION. CHILE
}

\author{
Víctor Campos ${ }^{1,2}$, Cristian Valenzuela ${ }^{1}$, Marcela Alcorta ${ }^{1}$, \\ Guisella Escalante ${ }^{1} \&$ María A. Mondaca ${ }^{1}$ \\ ${ }^{1}$ Departamento de Microbiología, Facultad de Ciencias Biológicas, Universidad de Concepción. \\ Casilla 160-C. Concepción, Chile. mmondaca@udec.cl. \\ ${ }^{2}$ Centro de Ciencias Ambientales EULA-CHILE, Universidad de Concepción, Casilla 160-C, Concepción, Chile.
}

\section{RESUMEN}

El arsénico se encuentra en estado natural en rocas, suelo, agua, aire y es liberado al ambiente mediante fenómenos naturales tales como erupciones volcánicas, erosión de las rocas e incendios forestales, donde los microorganismos son esenciales para el ecosistema por su participación en diferentes procesos naturales. El objetivo del trabajo fue aislar bacterias resistentes a arsénico, desde muestras de rocas provenientes de la Quebrada Camarones, región Parinacota, Chile. Las rocas fueron cultivadas en un medio mineral adicionado con arsenito $(500 \mathrm{ug} / \mathrm{ml})$ durante 7 días a temperatura ambiente y con agitación. Las cepas fueron aisladas en diferentes medios e identificadas mediante el sistema Rapid ${ }^{\mathrm{TM}} \mathrm{NF}$ plus. La capacidad de oxidar arsénico fue realizada mediante el ensayo cualitativo con nitrato de plata y la detección de genes aox, mediante RT-PCR. La reducción de arsénico fue evaluada mediante la amplificación de los genes ars por PCR. Se aislaron bacilos Gram negativos, no fermentadores, identificados como Pseudomonas alcaligenes y Wautersia solanacearum todas ellas capaces de tolerar concentraciones igual o mayor a $8 \mathrm{mM}$ de As(III). Los análisis mediante RT-PCR demuestran la presencia de genes aox, que codifica para una enzima oxidante que cataliza la oxidación de $\mathrm{As}(\mathrm{III})$ a As(V). La capacidad de oxidar arsenito de las cepas aisladas, favorecería la colonización de otras especies no tolerantes a arsénico importantes en los ciclos biogeoquímicos.

Palabras claves: Arsenito, arseniato, Wautersia solanacearum, Pseudomonas alcaligenes.

\section{ABSTRACT}

Arsenic is naturally present in rocks, soil, water, and air, being released to the environment by natural processes such as volcanic eruptions, and erosion rock. Microorganisms are known to play an important role in the Arsenic natural cycle. The aim of this work was isolate arsenic resistant bacteria to volcanic rocks, from Quebrada Camarones, Parinacota Region, Chile. Rocks were cultured in an arsenite conditioned mineral broth $(500 \mathrm{ug} / \mathrm{mL})$ over 7 days at ambient temperature, under stirring. Strains were isolated using different medium and identified by Rapid ${ }^{\mathrm{TM}}$ NF plus system. The arsenic oxidation capacity was assayed with silver nitrate, and aox genes were detected by RT-PCR. Arsenic reduction was evaluated means ars gene amplification by PCR. Gram negative no fermentative bacillum, identified as Pseudomonas alcaligenes and Wautersia solanacearum able to tolerate concentrations above $8 \mathrm{mM} \mathrm{As(III)} \mathrm{were}$ isolated. RT-PCR analysis showed the presence of aox, genes; these codify an oxidant enzyme that catalyses As(III) oxidation to $\mathrm{As}(\mathrm{V})$. The Arsenic oxidation capacity of the isolated seeds would favor colonization by other non tolerant species participating in biogeochemical cycles.

Keywords: Arsenite, arseniate, Wautersia solanacearum, Pseudomonas alcaligenes. 


\section{INTRODUCCION}

El arsénico está presente en cantidades abundantes en la corteza terrestre y en cantidades más reducidas en rocas, suelo, agua y el aire, además está presente en numerosos minerales. Alrededor de un tercio del arsénico presente en la atmósfera proviene de fuentes naturales, por ejemplo de los volcanes, y el resto de actividades antropogénicas. Cuando hay contaminación geológica natural, se pueden encontrar altos niveles de arsénico en aguas subterráneas, como es el caso de Bangladesh, Mongolia, China, Taiwán, entre otros. En la zona norte de Chile, la Quebrada de Camarones, por su carácter volcánico y las datas geológicas del periodo cuaternario generan condiciones favorables para el enriquecimiento de las aguas superficiales y subterráneas con arsénico, por la presencia de minerales arseniosos, asociados a la composición mineralógica del material volcánico y el clima caluroso, que eleva significativamente la temperatura en el medio de reacción entre los sólidos arsenicales y el agua (Kulp et al. 2004).

El arsénico se encuentra en las aguas naturales como especie soluble, producto de la movilización de éste desde rocas y suelos erosionados, el cual se presenta por lo común como oxianiones con el arsénico en dos estados de oxidación, arsénico trivalente [As(III)] y arsénico pentavalente $[\mathrm{As}(\mathrm{V})]$, y con menos frecuencia como As(0), As(-I) y As(-II). El $\mathrm{As}(\mathrm{V})$ está presente a la forma $\mathrm{H}_{3} \mathrm{AsO}_{4}$ y sus correspondientes productos de disociación $\left(\mathrm{H}_{2} \mathrm{AsO}_{4}^{-}, \mathrm{HasO}_{4}{ }^{2-}\right.$ y $\left.\mathrm{AsO}_{4}{ }^{3-}\right)$. El As(III) aparece como $\mathrm{H}_{3} \mathrm{AsO}^{3}$ y sus correspondientes productos de disociación $\left(\mathrm{H}_{4} \mathrm{AsO}_{3}+, \mathrm{H}_{2} \mathrm{AsO}^{3-}, \mathrm{HasO}_{3}{ }^{2-} \mathrm{y} \mathrm{AsO}_{3}{ }^{3-}\right)$. Aunque tanto As(V) como As(III) son móviles en el medio, es precisamente el As(III) el estado más lábil y biotóxico (Cullen \& Reimer 1989).

La presencia de As (V) y As (III) depende de factores físicos, químicos y biológicos, en este último, los microorganismos juegan un papel fundamental, ya que muchas bacterias son capaces de transformar As(III) a As(V) y viceversa (Macur et al. 2004). La capacidad de transformar arsénico ha sido descrita como un mecanismo de defensa de algunas especies bacterianas. Esta estrategia esta asociada a la alternancia entre células en estado planctónico y las mismas células en estado béntico y sésil, formando biopelículas (biofilms), comportamiento muy utilizado en medios acuáticos oligotróficos, que beneficia la presencia de diferentes bacterias no tolerantes a este metaloide, las que juegan un rol de importancia en los ciclos biogeoquímicos.

El objetivo del presente trabajo fue aislar bacterias resistentes a arsénico e investigar desde muestras de rocas volcánicas provenientes de la quebrada Camarones, I Región, Chile.

\section{MATERIALES Y METODOS}

\section{Sitio De MUeStReo}

Las muestras de rocas volcánicas fueron obtenidas de los sectores Illapata, Esquiña y Desembocadura, de la Quebrada Camarones $\left(19^{\circ} 00\right.$ Sur y $\left.69^{\circ} 47\right)$, I Región, Chile.

\section{Aislamiento E IDENTIFICACIÓN BACTERIANA}

Las rocas volcánicas, fueron incubadas en un medio químicamente definido (MQD) (Muller et al. 2003) conteniendo $500 \mathrm{ug} / \mathrm{ml}$ de arsenito de sodio, durante 10 días a temperatura ambiente. Para el aislamiento de cepas bacterianas, las rocas fueron sonicadas por 5 minutos, en un sonicador (Transsonic T310, Elma) y alícuotas del sobrenadante fueron sembradas en agar Cetrimide, R2A, MQD. Se seleccionaron diferentes bacterias y se determinaron los niveles de resistencia a arsénico (III) y (V). Todas las cepas seleccionadas fueron identificadas por el sistema RapID One y RapID NF plus (REMEL company), de acuerdo a las indicaciones de los proveedores.

\section{DETERMINACIÓN DE NIVELES DE TOLERANCIA}

Los niveles de tolerancia se determinaron mediante la técnica de dilución seriada en placa (NCCL, 1992). Se utilizó agar Luria adicionado de concentraciones variables de arsenito de sodio o arseniato de sodio $(8,6,4,2,1,0.5,0.1 \mathrm{mM})$. Cada una de las placas se inoculó con diluciones apropiadas de cultivos bacterianos de $24 \mathrm{~h}$ de incubación. Como control, se inocularon placas con agar Luria, sin arsénico. Las placas se incubaron a $25^{\circ} \mathrm{C}$ durante 24 a $48 \mathrm{~h}$ y se observó la presencia de desarrollo bacteriano (Muller et al. 2003).

\section{DETERMINACIÓN DE PROPIEDADES OXIDATIVAS}

Las cepas seleccionadas se sembraron en placas de agar Luria sin y con As (III) (100mgL-1) y As (V) $\left(200 \mathrm{mgL}^{-1}\right)$. Las placas se incubaron a $25^{\circ} \mathrm{C}$, 
durante 72 h. A cada una de las placas se les adicionó una solución de $\mathrm{AgNO}_{3}(0,1 \mathrm{M})$. El $\mathrm{AgNO}_{3}$ con As (III) produce un complejo de color amarillo y con As (V) de color café (Simeonova et al. 2004).

DETECCIÓn Genesars POR PCR.

El ADN total se obtuvo a partir de un cultivo de cada una de las cepas en caldo Luria de 18 a $24 \mathrm{~h}$ de incubación a $25^{\circ} \mathrm{C}$, utilizando el kit Instagene тм Matrix (BioRad), de acuerdo a las instrucciones de los proveedores.

La presencia de los genes ars $A B C$, se detectó mediante PCR utilizando como partidores mencionados en la Tabla I.

La PCR se realizó en un termociclador Px2 Thermal cycler (Thermo, electron Corporation). La mezcla de reacción estuvo compuesta por buffer Tris-Hcl (pH 8.3) 10 mM, $50 \mathrm{mM} \mathrm{Kcl,} 2.0 \mathrm{mM}$ $\mathrm{MgCl}_{2}, 200 \mathrm{nM}$ de cada partidor, $0.625 \mathrm{U}$ de $\mathrm{Taq}$ polimerasa (Perkin-Elmer or Promega) por $25 \mu 1$, y $50 \mathrm{ng}$ ADN (templado). El protocolo de amplificación para cada partidor fue el siguiente: Paso inicial de denaturación $\left(94^{\circ} \mathrm{C}\right.$ por $\left.3 \mathrm{~min}\right)$ seguido por 30 a 35 ciclos de $94^{\circ} \mathrm{C}$ por $30 \mathrm{~s}, 58^{\circ} \mathrm{C}$ por $30 \mathrm{~s}$ y $72^{\circ} \mathrm{C}$ por $30 \mathrm{~s}(\operatorname{ars} A-1)$ o 30 a 35 ciclos de $94^{\circ} \mathrm{C}$ por $30 \mathrm{~s}, 59^{\circ} \mathrm{C}$ por $30 \mathrm{~s}, \mathrm{y} 72^{\circ} \mathrm{C}$ por $30 \mathrm{~s}$ (arsB-1 y $\operatorname{ars} C$-1). La extensión final se realizó por $7 \mathrm{~min}$ a $72^{\circ} \mathrm{C}$. Agua desionizada fue utilizada como control negativo. Los productos de amplificación (alícuotas de 5- a 10- $\mu 1$ ) fueron separados mediante electroforesis en gel de agarosa al $2 \%(0.5 \mu \mathrm{g}$ de bromuro de etidio por $\mathrm{ml}$ ). Las bandas fueron visualizadas en un transiluminator UV (Saltikov \& Olson 2002)

EXTRACCIÓN DE ARN y RT-PCR.

Los cultivos bacterianos fueron inducidos, antes de la extracción, adicionando $50 \mathrm{ug} / \mathrm{ml}$ de As(III) durante $1 \mathrm{~h}$. Las bacterias fueron peleteadas por centrifugación y el ARN total fue extraído con el KIT E.Z.N.A. total ARN Kit. (Omega, Bio-Tek), de acuerdo a las instrucciones de los fabricantes. Las muestras de ARN fueron tratadas con Dnasa I (Gibco-BRL) y cuantificada en un espectrofotómetro a $260 \mathrm{~nm}$.

El ARN total libre ADN fue transcrito en reversa y posteriormente amplificado por PCR con los partidores "a" (5'-AATGACACCTTCACGGCG3'), el cual se une a 48 bp río arriba del codon final aoxA, y el partidor " $\mathrm{b}$ " (5'AGCACTCGATCTT-TTGCAG-3'), a 872 bp río abajo del codon inicial $a o x B$, usando una transcriptasa reversa M-MuLV (LabBios). La transcripción reversa fue realizada a $42^{\circ} \mathrm{C}$ por 1 $\mathrm{h}$, seguido de una amplificación por PCR, la que consistió en 10 ciclos de $95^{\circ} \mathrm{C}$ por $30 \mathrm{~s}, 54^{\circ} \mathrm{C}$ por $30 \mathrm{~s}$, y $68^{\circ} \mathrm{C}$ por $45 \mathrm{~s}$; seguido de 25 ciclos donde el tiempo de elongación fue incrementando en $5 \mathrm{~s}$ por cada ciclo; finalmente se realizó una elongación final de 10 min. Los productos de RTPCR fueron examinados mediante electroforesis en un gel de agarosa al 2\% (Muller et al. 2003).

\section{RESULTADOS.}

IDENTIFICACIÓN Y NIVELES DE RESISTENCIA

Se aislaron 10 cepas bacterianas desde tres rocas volcánicas de cada uno de los sectores en estudio. Las cepas bacterianas fueron identificadas en base a sus propiedades bioquímicas, mediante el sistema de identificación Rapid One. En la muestra proveniente del sector Illapata, se aisló una cepa de Pseudomonas alcaligenes y Wautersia solanacearum, con niveles de resistencia $>8$ y 2 mM, para As(III) y As(V) respectivamente. Además se aislaron una cepa de Acinetobacter calcoaceticus y Enterobacter cloacae, donde sus niveles de resistencia a As (III) y As (V), fueron de 2 y $>8 \mathrm{mM}$ respectivamente.

En el sector Esquiña se aisló una cepa de Wautersia solanacearum, con niveles de resistencia de 8 y $3 \mathrm{mM}$, una cepa de Pseudomonas alcaligenes con niveles de resistencia de 8 y $1 \mathrm{mM}$, Burkordelia cepacia con niveles de resistencia de 8 y $1 \mathrm{mM}$ y una Enterobacter cloacae con niveles de resistencia de 8 y $1 \mathrm{mM}$, para $\mathrm{As}(\mathrm{III})$ y $\mathrm{As}(\mathrm{V})$, respectivamente.

En el sector desembocadura se aisló una cepa bacteriana correspondiente a Wautersia solanacearum con niveles de resistencia de $>8$ y $3 \mathrm{mM}$ y una cepa de Burkordelia cepacea con niveles de resistencia de 1 y $>8 \mathrm{mM}$, para As(III) y As(V), respectivamente (Tabla I).

DETECCIÓN DE PROPIEDADES OXIDANTES Y REDUCTORAS DE LAS CEPAS AISLADAS

Utilizando un test colorimétrico a base de $\mathrm{AgNO}_{3}$ (Simeonova 2002), se investigó la transformación 
Aislamiento de bacterias resistentes a arsénico: CAMPOS, V. ET AL

bacteriana de arsénico de las 10 cepas en estudios. Se detectaron propiedades oxidantes en 5 cepas bacterianas, $P$. alcaligenes y $W$. solanacearum, para los sectores de Illapata y Esquiña. En el sector de desembocadura sólo se aisló $P$. alcaligenes con capacidad de oxidar arsénico.

En cambio, A. calcoaceticus y E. cloacae en el sector de Illapata y B. cepacia y E. cloacae en el sector Esquiña presentaron actividad arseniato-reductora. En el sector Desembocadura se aisló B. cepacia con esta capacidad (Tabla II).
DETECCIÓN DE LOS GENES AOX Y ARS

La detección de los genes aox y ars de las 10 cepas de bacilos Gram negativos en estudio se muestra en la tabla II. En los tres sectores en estudio se detectaron cepas bacterianas con capacidad de reducir y oxidar arsénico, detectando que en todos los sectores, tanto Pseudomonas alcaligenes y Wautersia solanaceaum presentaron los genesaox que les otorga la capacidad de oxidar arsénico, en cambio en las cepas Burkholderia, Enterobacter y Acinetobacter se detectó la presencia del operonars.

TABLA I. Niveles de tolerancia a arsénico de 10 cepas de bacilos Gram negativos, aislados desde rocas volcánicas, de la Quebrada Camarones, Región Parinacota, Chile.

TABLE I. Tolence Levels to arsenic of 10 bacille Gram negative strains, isolated to volcanic rocks, from Quebrada Camarones, Parinacota region, Chile.

\begin{tabular}{llll}
\hline & & \multicolumn{2}{l}{ Niveles de Tolerancia $(\mathrm{mM})$} \\
\hline Cepas Bacteriana & Lugar & As(III) & As $(\mathrm{V})$ \\
\hline$P$. alcaligenes & Illapata & $>8$ & 2 \\
$W$. solanaceaum & Illapata & $>8$ & 2 \\
A. calcoaceticus & Illapata & 2 & $>8$ \\
E. cloacae & Illapata & 2 & $>8$ \\
\hline W. solanaceaum & Esquiña & $>8$ & 4 \\
$P$. alcaligenes & Esquiña & $>8$ & 1 \\
B. cepacia & Esquiña & 1 & $>8$ \\
E. cloacae & Esquiña & 4 & 3 \\
\hline W. solanaceaum & Desembocadura & $>8$ & $>8$ \\
B. cepacia & Desembocadura & 1 & \\
\hline
\end{tabular}

TABLA II. Caracterización molecular de 10 cepas Gram negativas aisladas desde rocas volcanicas, Quebrada Camarones, Región de Parinacota, Chile.

TABLE II. Molecular characterization of 10 strains Gram negative isolated from volcanic rocks, Quebrada Camarones, Parinacota Region, Chile.

\begin{tabular}{lllll}
\hline Cepa & Lugar & AgNo3* & arsABC** & Aox*** \\
\hline$P$. alcaligenes & Illapata & + & - & + \\
$W$. solanaceaum & Illapata & + & - & + \\
A. calcoaceticus & Illapata & - & + & - \\
E. cloacae & Illapata & - & + & - \\
\hline W. solanaceaum & Esquiña & + & - & + \\
$P$. alcaligenes & Esquiña & + & - & + \\
$B$. cepacia & Esquiña & - & + & - \\
E. cloacae & Esquiña & - & + & + \\
\hline W. solanaceaum & Desembocadura & + & - & - \\
$B$. cepacia & Desembocadura & - & + & + \\
\hline
\end{tabular}

*Actividad oxidante (Cualitativo); ** Amplificación por PCR operon $\operatorname{ars} A B C$;

$* * *$ RT-PCR del gen aox 


\section{DISCUSION}

En la literatura existen pocos trabajos relacionados con el aislamiento de bacterias resistentes arsénico desde rocas volcánicas, donde la mayoría están orientados al aislamiento de un microorganismo con la capacidad de tolerar la presencia del metal, sin determinar la importancia y su rol ecológico.

La presencia de arsénico en la composición mineralógica de las rocas volcánicas (Dato no mostrado), obtenidas de la Quebrada Camarones, favorecería el aislamiento de bacterias resistentes a arsénico, principalmente a especies con una gran versatilidad metabólica, los cuales pueden estar basados en sistemas genéticos a nivel plasmidial o cromosomal (Cai et al. 1998). Basado en esto, los microorganismos han desarrollado diversos mecanismos para supervivir a la toxicidad del arsénico, entre ellos se puede mencionar las transformaciones del arsénico entre el arsenito (As(III)) y arseniato (As(V)).

La reducción microbiana de arsénico ha sido reportada en numerosos géneros incluyendo Alcaligenes, Escherichia, Pseudomonas, Bacillus, Desulfovibrio, Shewanella, Enterobacter, Thauera, $\mathrm{y}$ en numerosos géneros dentro de Cyanobacteria y de bacterias reductoras de sulfatos (Yamamura et al. 2003; Niggemyer et al. 2001; Macy et al. 2000; Saltikov et al. 2003). En este trabajo se aislaron cepas correspondientes a los génerosEnterobacter, Acinetobacter y Burkholderia capaces de crecer a elevadas concentraciones de arsénico. La resistencia a $\mathrm{As}(\mathrm{V})$ ha sido descrito por otros autores (Ji \& Silver 1992; Jackson \& Dugas, 2003; McEwan et al. 2002; Macy et al. 2000; Neyt et al. 1997) los cuales mencionan que dicha capacidad se debería a la presencia del operón ars, responsable de la reducción de $\mathrm{As}(\mathrm{V})$ y que el posible mecanismo de adquisición del sistema, sería una transferencia horizontal de genes, vía plásmidos o transposones. La capacidad de Wautersia solanacearum de reducir arseniato ha sido reportado por otros autores, pero sólo desde cepas aisladas de suelos. Esta trabajo describe el primer reporte de aislamiento una cepa de Wautersia solanaceaum desde rocas, además con la capacidad de oxidar arsenito.

Por otro lado, existen numerosas especies bacterianas capaces de oxidar arsénico y utilizar este compuesto como dador de electrones para el crecimiento quimiolitotrofo (Weeger et al. 1999;
Santini etal. 2000; Santini \& Hoven, 2004; Oremland et al. 2002), aunque muy pocos microorganismos pueden crecer a través de este mecanismo, entre estos se encuentra Pseudomonas arsenitoxidans, cepa NT-26 aislada de muestras de arsenopirita desde una mina de oro. Entre otras bacteria descritas capaces de oxidar arsénico se encuentran Achromobacter (Alcaligenes) faecalis, Agrobacterium albertimagni AOL15,Pseudomonas putida ULPAs1 (Cenibacterium arsenoxidans), (Osborne \& Enrlich, 1976; Salmassy et al. 2002 Oremland et al. 2003; Santini et al. 2000; Ilialetdinov et al. 1981; Weeger et al. 1999; Anderson et al. 1992). En este estudio se aislaron dos cepas bacterianas capaces de oxidar arsenito, determinado mediante la detección de los genesaox, mediante PCR. $P$ alcaligenes, cepa aislada desde los tres sectores en estudio, no ha sido descrita como una bacteria capaz de oxidar arsénico, sin embargo, este género presenta una gran versatilidad metabólica, lo que podría explicar esta capacidad. En literatura existen reportes relacionados a otras especies del género Pseudomonas con capacidad de oxidar arsenito (Anderson et al. 1992; Phillips et al. 1976; Weeger et al. 1999; Mokashi \& Paknikar 2002).

La transformación microbiana de arsénico puede indirectamente influenciar el ciclo biogeoquímico del arsénico, además la capacidad de algunas especies, como es el caso de acidithiobacillus, de liberar arsénico desde minerales como arsenopirita y arginita a través de la oxidación del arsénico, beneficiaria la colonización de la roca por otras bacterias no resistentes al metaloide.

\section{AGRADECIMIENTOS}

Este trabajo fue financiado por el proyecto FONDECYT No 1050088 y proyecto DIUC $\mathrm{N}^{\circ}$ 204.036.027-1.0.

\section{BIBLIOGRAFIA}

Anderson, G.,Williams, J. \& Hille, R. 1992. The purification and characterization of arsenite oxidase from Alcaligenes faecalis: a molybdenum containing hydroxylase. J. Biol. Chem. 267: 23674-23682. 
Aislamiento de bacterias resistentes a arsénico: CAMPOS, V. ET AL

CaI, J., SAlmon, K. \& Dubow, M.1998. A chromosomal ars operon homologe of Pseudomonas aeruginosa confers increased resistance to arsenic and antimony in Escherichia coli. Microbiol. 144:2705-2713.

Cullen, W. R. \& K. J. Reimer. 1989. Arsenic speciation in the environment. Chem. Rev. 89:713-764.

Ilyaletdonov, A.N. \& S.A. Abdrashitova.1981. Autotrophic oxidation of arsenic by culture of Pseudomonas arsenoxidants. Mikrobiologiia. 50:197-204

JACKSON, C.R. \& S.L. Dugas. 2003. Phylogenetic analysis of bacterial and archaeal arsC gene sequences suggest an ancient, common origin for arsenate reductase. BMC Evolucionary Biology. 3:18.

Ji, G. \& S. Silver. 1992. Regulation and expression of the arsenic resistance operon from Staphylococcus aureaus plasmid p1258. J Bacteriol. 174:36843694.

Kulp, T. R., S.E. Hoeft \& R. S. ORemland. 2044. Redox transformations of arsenic oxyanions in periphyton communities. Applied and Environmental Microbiology. 70(11): 64286434

M acur, R., C. Jackson, L. Botero, T. McDermott \& W. INSKEEP. 2004. Bacterial populations associated with the oxidation and reduction of arsenic in an unsaturated soil. Environ Sc. Techn environ. 38 : 104-111.

Macy, J.M., J.M. SAntini, B.V. Pauling, A.H. O’Neil \& L.I. SLy. 2000. Two new arsenate/sulfate- reducing bacteria: mechanisms of arsenate reduction. Arch. Microbiol.173:49-57.

McEwan, A.G., J.P. Ridge, C.A. Mcdevitt \& P. Hugenholts. 2002. The DMSO reductase family of molybdenum enzymes; molecular properties and role in the dissimilatory reduction of toxic element. Geomicrobiol. J. 19: 3-21.

Mokashi S. A \& K. M. Paknikar. 2002. Arsenic (III) oxidizing Microbacterium lacticum and its use in the treatment of arsenic contaminated groundwater. Letters in Applied Microbiology 34: 258-262.

Muller, D., D. Lievremont, D.D. Simeonova, J.C. Hubert \& M.C. LetT. 2003. Arsenite oxidase aox genes from a metal resistant beta-proteobacterium. J.Bacteriol.185:135-141.

NCCL (1992). National Committee for Clinical Laboratory Standards Performance standards for antimicrobial disk susceptibility tests fourth edition; Approved Standard NCCLS Document M2-A4, Villanora.

Neyt, C.N., M. Iriarte, V.H. Thi \& G.R. Cornelis. 1997. Virulence and arsenic resistance in Yersiniae. J. Bacteriol. 179:612-619.
Niggemyer, A., S. Spring, E. Stackebrandt \& R.F. RoSENZWEIG. 2001. Isolation and characterization of a novel As(V)-reducing bacterium: implications for arsenic mobilization and genus Desulfitobacterium. Applied and Environmental Microbiology, 67: 5568-5580.

OsborNe, F.H.\& H.L. EhrLich.1976. Oxidation of arsenite by soil isolate of Alcaligenes J. Appl. Bacteriol. 41: 295-305.

Oremland, R. S. \& J. F. Stolz. 2003. The ecology of arsenic. Science 300(5621):939-44.

Phillips, S.E., \& M.L. TAYLOR. 1976. Oxidation of arsenite to arsenate by Alcaligenes faecalis. Appl. Environ. Microbiol., 32, 392-399.

Salmassi T. M, J.J. Walker, D.K. Newman, J.R. Leadbetter, N.R. Pace \& J. G. Hering. 2005. Community and cultivation analysis of arsenite oxidizing biofilms at Hot Creek. Environmental Microbiology 7 (13): 1654-1668.

Saltikov, C.W., A. Cifuentes, K. Venkateswaran \& D.K. Newman. 2003. The ars detoxification system is advantageous but not required for $\mathrm{As}(\mathrm{V})$ respiration by the genetically tractable Shewanella species strain ANA-3. Applied and Environmental Microbiology, 69: 2800-2809.

Saltikov, C. W. \& B.H. Olson. 2002. Homology of Escherichia coli $\mathrm{R} 773$ ars $A$, ars $B$, ars $C$ genes in arsenic-resistant bacteria isolated from raw sewage and arsenic-enriched creek waters. Applied and Environmental Microbiology. 68(1):280-288.

SAntini, J. M., L.I. Sly, R.D. Schnagl \& J.M. M acy. 2000. A new chemolithoautrofic arsenite-oxidizing bacterium isolated from a gold mine: phylogenetic, physiologycal, and preliminary biochemical studies. Appl. Environ. Microbiol.66:92-97.

Santini, J.M. \& R.N. Hven. 2004. Molybdenumcontaining arsenite oxidase of the chemolithoautotrophic arsenite oxidizer NT-26. J. Bacteriol.186:1614-1619.

Simeonova, D.D., D. Lievremont, F. Lagarde, D.A. Muller, V.I. Groudeva \& M. C. Lett . 2004. Microplate screening assay for the detection of arsenite-oxidizing and arsenate-reducing bacteria. FEMS Microbiol Letters. 237(2):249-53.

Yamamura, S., M. Ike \& M. FujtTa. 2003. Dissimilatory arsenate reduction by a facultative anaerobe, Bacillus sp. strain SF-1. Journal of Bioscience and Bioengineering. 96: 454-460.

Weeger, W., D. Levremont, M. Perret, F. Lagarde, J.C. Hubert, M. Leroy \& M.C. Lett. 1999. Oxidation of arsenite to arsenate by a bacterium isolated from an aquatic environment. Biomet.12(2):141-149. 